\title{
주흘산의 곤충상
}

\author{
김 진 일* 강 태 화** \\ *성신여자대학교 생물학과 \\ **국립농업과학원 농업생물부
}

\section{Insect Faunistic Survey on Mt. Juheul}

\author{
$\mathrm{KIM}$, Jin $\mathrm{II}^{\star} \cdot$ Tae Hwa KANG** \\ * Department of Biology, Sungshin Women's University \\ **Department of Agricultural Biology, National Academy of Agricultural Science
}

\begin{abstract}
The faunistic survey on Mt. Juheul, Korea was presented. This survey was carried out by dividing as two part, reference search and field work. Through the result of the reference search, total of 80 species of 28 families under three orders were reported, and in a result of the field work, 125 species of 58 families under 13 orders were newly found. Therefore, it was newly confirmed that total 205 species of 74 families under 13 orders live in Mt. Juheul.
\end{abstract}

Key words : Academic survey, Korean Association for Conservation of Nature, Insect fauna, Mt. Juheul, Korea

서 론

주흘산은 행정구역상 경상북도 문경시 문경읍에 위치하며, 인근의 조령산, 포암산, 월악산 등과 함 께 소백산맥의 중심을 형성하고 있다. 해발 고도 $1,106 \mathrm{~m}$ 인 영봉을 중심으로 문경시 뒤편에 위치하 고 있는 주봉(해발 $1,075 \mathrm{~m}$ )과 부봉(해발 $917 \mathrm{~m}$ )을 지나 동화원으로 이어지는 능선이 잘 발달해 있으 며, 인근의 조령산과 함께 ‘조곡천'으로 알려진 계곡을 형성하고 있어 수려한 자연경관을 나타내고 있다. 역사적으로도 험한 산세를 이용하여 천애의 요새로 활용되기도 하였는데, 조곡천 동쪽면에 주 흘관(조령 제 1 관문), 조곡관(조령 제 2관문), 조령관(조령 제 3관문)의 세 관문과 원터, 성터 등의 문 화재가 많이 남아있어 1981년 6월 4일 문경새재도립공원이 지정되면서 이에 포함되었다.

주흘산의 곤충상 조사는 자연보존협회 종합학술조사를 통해 신(1978)에 의해 월악산과 함께 조사 된 것이 전부였다. 따라서, 현재까지 주흘산에서 공식적으로 보고되어 서식이 확인된 곤충 종수는 총 3 목 28 과 80 종이 전부였다. 이에 따라, 이번 조사에서는 주간 곤충을 중심으로 조사를 수행하였다.

이번 조사의 목적은 주흘산의 곤충상에 대한 재평가를 하고자 하였다. 이를 위해서 현지 조사를 통해 되도록 다양한 종류의 분류군을 채집하고자 하였다. 또한, 문헌 조사를 통해 기존 보고 종의 분 류군 특성을 분석하여 기존과 방법을 달리하여 채집을 수행하고자 하였다. 


\section{재료 및 방법}

\section{1. 현지조사}

주흘산 영봉을 중심으로 북동사면의 평천리(1), 동사면의 팔영리(2), 남동사면의 지곡리(3), 서남사 면의 하초리(4), 서북사면의 상초리(5) 등 총 5개 지점을 주요 거점으로 하여 조사하였다(Fig. 1). 이 중 평천리, 팔영리, 지곡리는 주변이 사과 과수원이 형성되어 있었으며, 조사는 되도록 사과 과수원 을 피해서 수행하고자 하였다. 서남사면의 하초리는 문경새재도립공원의 입구가 있는 지역으로 등산 객 및 관광객의 왕래가 잦았으며, 서북사면의 하초리는 계곡이 잘 발달되어 있는 곳으로 계곡을 따 라 조사를 수행하였다. 각 지역별 조사 시기를 보면, 평천리와 지곡리는 2011년 8월 19 20일, 팔영 리는 2011년 10월 2일, 하초리와 상초리는 2012년 6월 9일에 조사가 이루어졌다. 조사 방법은 주로 모니터링법을 활용하였으나, 현지에서 동정이 어려운 표본은 채집하여 표본 제작 후 동정을 수행하 였다.

\section{2. 문헌조사}

문헌 조사는 주로 자연보존협회의 종합학술보고서를 중심으로 수행되었다. 현재까지 보고된 곤충 상 조사 보고서 중 주흘산 관련 문헌은 신(1978)에 의한 것이 전부인 것으로 나타났다.

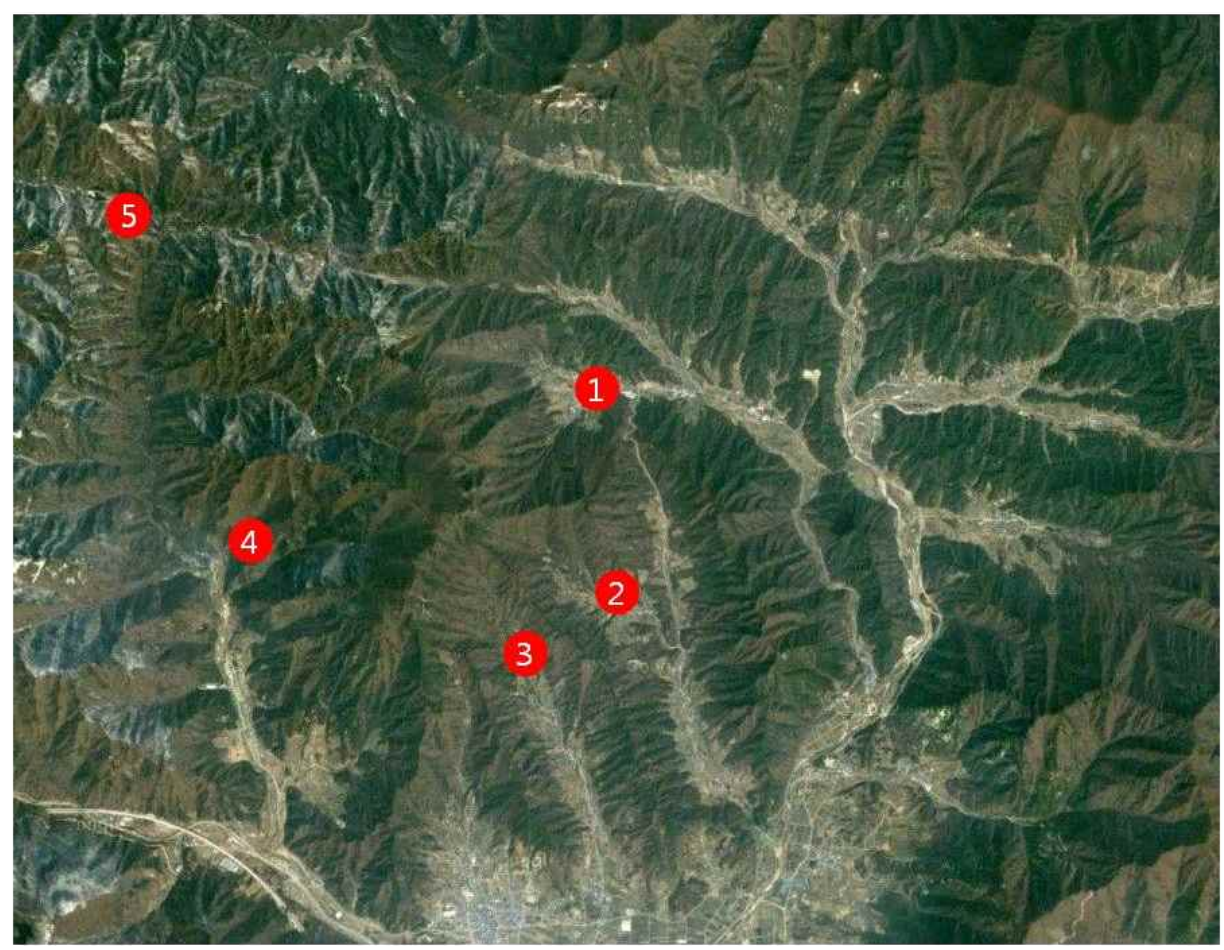

Fig. 1. Insect faunistic survey point in Mt. Juheul (1: Pyeongcheon-ri; 2: Palyeong-ri; 3: Jigok-ri; 4: Hacho-ri; 5: Sangcho-ri). 


\section{3. 채집표본분석}

채집된 표본은 분류군 별로 구분하여 표본 제작 후 동정하였다. 동정은 주로 분류군 별로 도감을 참고하여 가동정의 수준으로 이루어졌다. 주요 분류군 별 참고 도감은 다음과 같다: 잠자리목: 정 (2007); 노린재목: 안 등(2010); 매미목: 이(1979); 딱정벌레목: 박 등(2006); 벌목: Asahina et al. (2005); 파리목: Asahina et al. (2005); 나비목: 주 등(1997); 기타 곤충류: Asahina et al. (2005).

\section{결과 및 고찰}

\section{1. 문헌조사}

신(1978)에 의해 조사된 종수는 총 3목 28과 80종이 주흘산에 서식하는 것으로 보고된 바 있다(표 1). 분류학적 종 조성을 보면, 잠자리목 1과 1종, 딱정벌레목 10 과 16 종, 나비목 17 과 73 종이 포함되는 것으로 나타났다. 이 종들은 대부분 야간에 유화등을 이용한 채집법을 사용하였을 때 유인되는 종으 로 판단되었으며, 잠자리목의 날개띠좀잠자리(Sympetrum pedemontanum elatum), 딱정벌레목의 무당벌 레(Harmonia axyridis)와 큰이십팔점박이무당벌레(Henosepilachna vigintioctomaculata), 나비목의 나비류 등 17 종만이 낮에 채집이 가능한 종임을 확인할 수 있었다.

\section{2. 현지조사}

이번 조사에서 서식이 확인된 종수는 총 13 목 58 과 127 종으로 나타났다. 이들의 분류학적 조성은 돌좀목 1 과 1 종, 잠자리목 3 과 5 종, 사마귀목 1 과 1 종, 집게벌레목 1 과 1 종, 메뚜기목 6 과 16 종, 대벌 레목 1과 1종, 노린재목 7과 9종, 매미목 3과 7종, 딱정벌레목 14 과 36 종, 벌목 6과 14 종, 밑들이목 1 과 2종, 파리목 8 과 15종, 나비목 6과 19종으로 가장 많은 종이 확인된 분류군은 딱정벌레목으로 나 타났으나(Fig. 2, Table 1), 기록종 대비 확인종이 가장 많은 분류군은 돌좀목과 사마귀목으로 $25 \%$ 의 비율이었으며, 그 다음으로는 대벌레목으로 $20 \%$ 로 나타났다(Fig. 3). 또한, 가장 적은 비율로 확인된 목은 노린재목, 매미목, 딱정벌레목, 벌목, 파리목, 나비목 등 6 목에서 $1 \%$ 의 비율을 나타내었다. 이들 6 개 목은 국내에 기록종 수가 최소 690종에서 최대 3,702종으로 다른 목에 비해 비교적 종 다양성이 높은 것으로 알려져 있다(백 등, 2010). 이런 점으로 볼 때, 이들에 대한 추가 조사가 수행되어진다면 더욱 다양한 종의 출현이 예상된다.

\section{3. 종합적 고찰}

문헌조사 결과와 현지조사 결과를 종합해 보면, 주흘산에 서식하는 것으로 확인된 곤충의 총 종수 는 13 목 74 과 205 종으로 나타났다. 또한, 문헌조사 결과와 현지조사 결과의 종 조성을 비교해 보면, 딱정벌레목의 무당벌레와 나비목의 큰줄흰나비, 단 2종만 양쪽 조사 결과, 모두에서 확인된 것으로 나타났다. 이는 조사 방법에 기인하는 것으로 판단되는데, 기존의 신(1978)에 의한 조사는 주로 야간 에 출현하는 곤충들을 대상으로 하는 방법을 사용한 반면, 이번 조사에서는 주간에 출현하는 곤충을 대상으로 모니터링을 수행하였다. 이에 따라, 이번 조사를 통해서, 기존에 주흘산에서 알려져 있지 


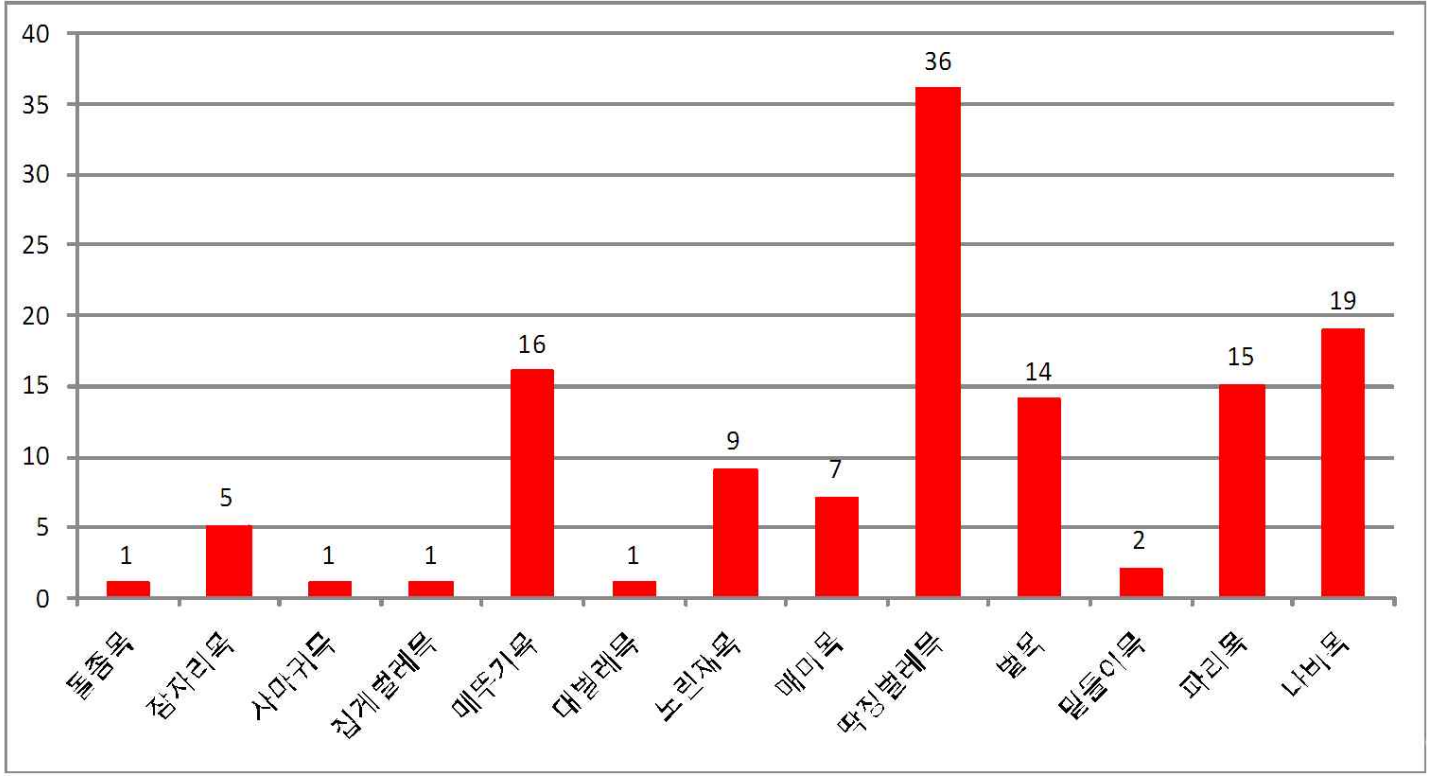

Fig. 2. Comparison of species composition of each insect order that was checked from Mt. Juheul.

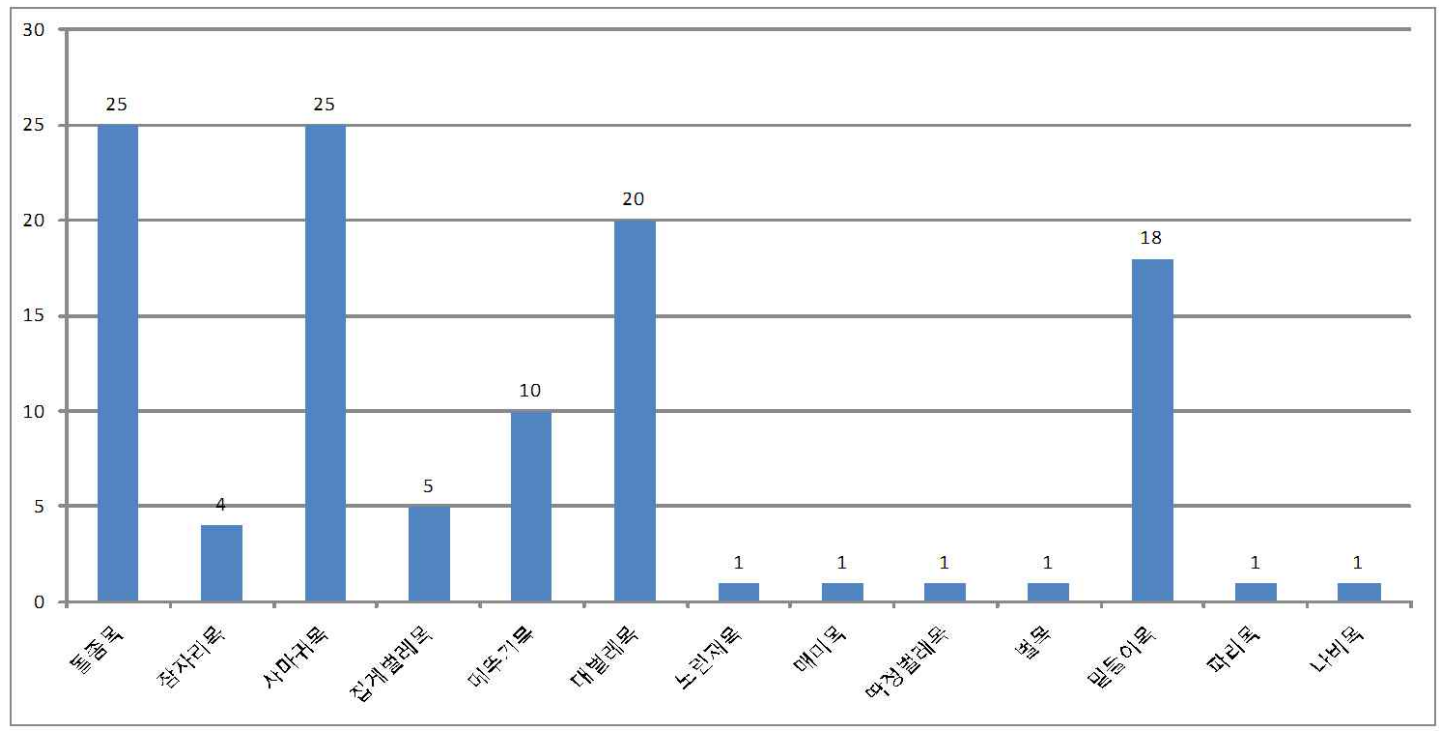

Fig. 3. Percentage of the number of species reported in Korea vs the number of species checked in Mt. Juheul.

않았던 125 종이 곤충상 목록에 추가되었다. 이런 점으로 미루어 볼 때, 다양한 채집 방법을 이용하여 조사한다면 보다 많은 종을 확인할 수 있을 것으로 판단된다. 또한, 현재의 결과는 짧은 기간 동안 각 지역별로 1 회씩의 조사를 통해 얻어진 것으로 조사 지점별 비교가 어려웠다. 이에 따라, 주기적인 지점 조사를 실시한다면 보다 명확한 곤충상을 규명할 수 있을 것으로 판단된다. 
Table 1. Species list from Mt. Juheul (1: Pyeongcheon-ri; 2: Palyeong-ri; 3: Jigok-ri; 4: Hacho-ri; 5: Sangcho-ri).

\begin{tabular}{|c|c|c|c|c|c|c|c|}
\hline No & Scientific name & 1 & 2 & 3 & 4 & 5 & Shin (1978) \\
\hline \multirow{5}{*}{1} & 1. Order Microcoryphia 돌좀목 & & & & & & \\
\hline & 1. Family Machilidae 돌좀과 & & & & & & \\
\hline & $\begin{array}{l}\text { Haslundichilis viridis Lee et Choe } \\
\text { 납작돌좀 }\end{array}$ & & & & 1 & & \\
\hline & 2. Order Odonata 잠자리목 & & & & & & \\
\hline & 2. Family Calopterygidae 물잠자리과 & & & & & & \\
\hline 2 & $\begin{array}{l}\text { Calopteryx atrata Selys } \\
\text { 검은물잠자리 }\end{array}$ & & & & 1 & & \\
\hline 3 & $\begin{array}{l}\text { Calopteryx japonica Selys } \\
\text { 물잠자리 }\end{array}$ & & & & 2 & & \\
\hline \multirow{3}{*}{4} & 3. Family Corduliidae 북방잠자리과 & & & & & & \\
\hline & $\begin{array}{l}\text { Macromia amphigena fraenata Martin } \\
\text { 잔산잠자리 }\end{array}$ & & & & 1 & & \\
\hline & 4. Family Libellulidae 잠자리과 & & & & & & \\
\hline 5 & $\begin{array}{l}\text { Sympetrum depressiusculum (Selys) } \\
\text { 고추좀잠자리 }\end{array}$ & & & 18 & & & \\
\hline 6 & $\begin{array}{l}\text { Sympetrum infuscatum (Selys) } \\
\text { 깃동잠자리 }\end{array}$ & & & 1 & & & \\
\hline \multirow[t]{2}{*}{7} & $\begin{array}{l}\text { Sympetrum pedemontanum elatum (Selys) } \\
\text { 날개띠좀잠자리 }\end{array}$ & & & & & & 1 \\
\hline & $\begin{array}{l}\text { 3. Order Mantodea 사마귀목 } \\
\text { 5. Family Mantidae 사마귀과 }\end{array}$ & & & & & & \\
\hline \multirow[t]{2}{*}{8} & $\begin{array}{l}\text { Tenodera aridifolia (Stoll) } \\
\text { 왕사마귀 }\end{array}$ & & & 1 & & & \\
\hline & $\begin{array}{l}\text { 4. Order Dermaptera 집게벌레목 } \\
\text { 6. Family Forficulidae 집게벌레과 }\end{array}$ & & & & & & \\
\hline \multirow[t]{2}{*}{9} & $\begin{array}{l}\text { Anechura japonica (Bormans) } \\
\text { 좀집게벌레 }\end{array}$ & & 1 & & & & \\
\hline & $\begin{array}{l}\text { 5. Order Orthoptera 메뚜기목 } \\
\text { 7. Family Tettigoniidae 여치과 }\end{array}$ & & & & & & \\
\hline 10 & $\begin{array}{l}\text { Elimaea grandis (Matsumura et Shiraki) } \\
\text { 큰실베짱이 }\end{array}$ & & & 2 & & & \\
\hline
\end{tabular}




\begin{tabular}{|c|c|c|c|c|c|c|c|}
\hline No & Scientific name & 1 & 2 & 3 & 4 & 5 & Shin (1978) \\
\hline 11 & $\begin{array}{l}\text { Conocephalus chinensis (Redtenbacher) } \\
\text { 쌕새기 }\end{array}$ & & & 13 & & & \\
\hline 12 & $\begin{array}{l}\text { Paratlanticus ussuriensis (Uvarov) } \\
\text { 갈색여치 }\end{array}$ & & & & 4 & & \\
\hline & 8. Family Oecanthidae 긴꼬리과 & & & & & & \\
\hline 13 & $\begin{array}{l}\text { Oecanthus indicus Saussure } \\
\text { 긴꼬리 }\end{array}$ & & & 7 & & & \\
\hline & 9. Family Gryllidae 귀뚜라미과 & & & & & & \\
\hline 14 & $\begin{array}{l}\text { Loxoblemmus arietulus Saussure } \\
\text { 알락귀뚜라미 }\end{array}$ & & & 4 & & & \\
\hline 15 & $\begin{array}{l}\text { Loxoblemmus doenitzi Stein } \\
\text { 모대가리귀뚜라미 }\end{array}$ & & & 2 & & & \\
\hline 16 & $\begin{array}{l}\text { Teleogryllus emma (Ohmachi et Matsumura) } \\
\text { 왕귀뚜라미 }\end{array}$ & & & 1 & & & \\
\hline 17 & $\begin{array}{l}\text { Polionemobius mikado (Shiraki) } \\
\text { 좀방울벌레 }\end{array}$ & & 3 & & & 2 & \\
\hline 18 & $\begin{array}{l}\text { Paratrigonidium bifasciatum Shiraki } \\
\text { 풀종다리 }\end{array}$ & & & 3 & & & \\
\hline 19 & $\begin{array}{l}\text { Homoeogryllus japonicus (deHaan) } \\
\text { 방울벌레 }\end{array}$ & & & 1 & & & \\
\hline & 10. Family Tetrigidae 모메뚜기과 & & & & & & \\
\hline 20 & $\begin{array}{l}\text { Tetrix japonica (Bolivar) } \\
\text { 모메뚜기 }\end{array}$ & & & & 2 & 1 & \\
\hline & 11. Family Pyrgomorphidae 섬서구메 뚜기과 & & & & & & \\
\hline 21 & $\begin{array}{l}\text { Atractomorpha lata (Motschulsky) } \\
\text { 섬서구메뚜기 }\end{array}$ & & & & 1 & & \\
\hline & 12. Family Acrididae 메뚜기과 & & & & & & \\
\hline 22 & $\begin{array}{l}\text { Anapodisma miramae Dovnar-Zapol'skii } \\
\text { 밑들이메뚜기 }\end{array}$ & & & 1 & & & \\
\hline 23 & $\begin{array}{l}\text { Ogneviasergii ikonnikovi Rehnet-Rehn } \\
\text { 원산밑들이메 뚜기 }\end{array}$ & & & & & 1 & \\
\hline 24 & $\begin{array}{l}\text { Mongolotettix japonicus (Bolivar) } \\
\text { 삽사리 }\end{array}$ & & & & 5 & 1 & \\
\hline 25 & $\begin{array}{l}\text { Podismopsis genicularibus (Shiraki) } \\
\text { 검정무릎삽사리 }\end{array}$ & & & & 1 & & \\
\hline
\end{tabular}




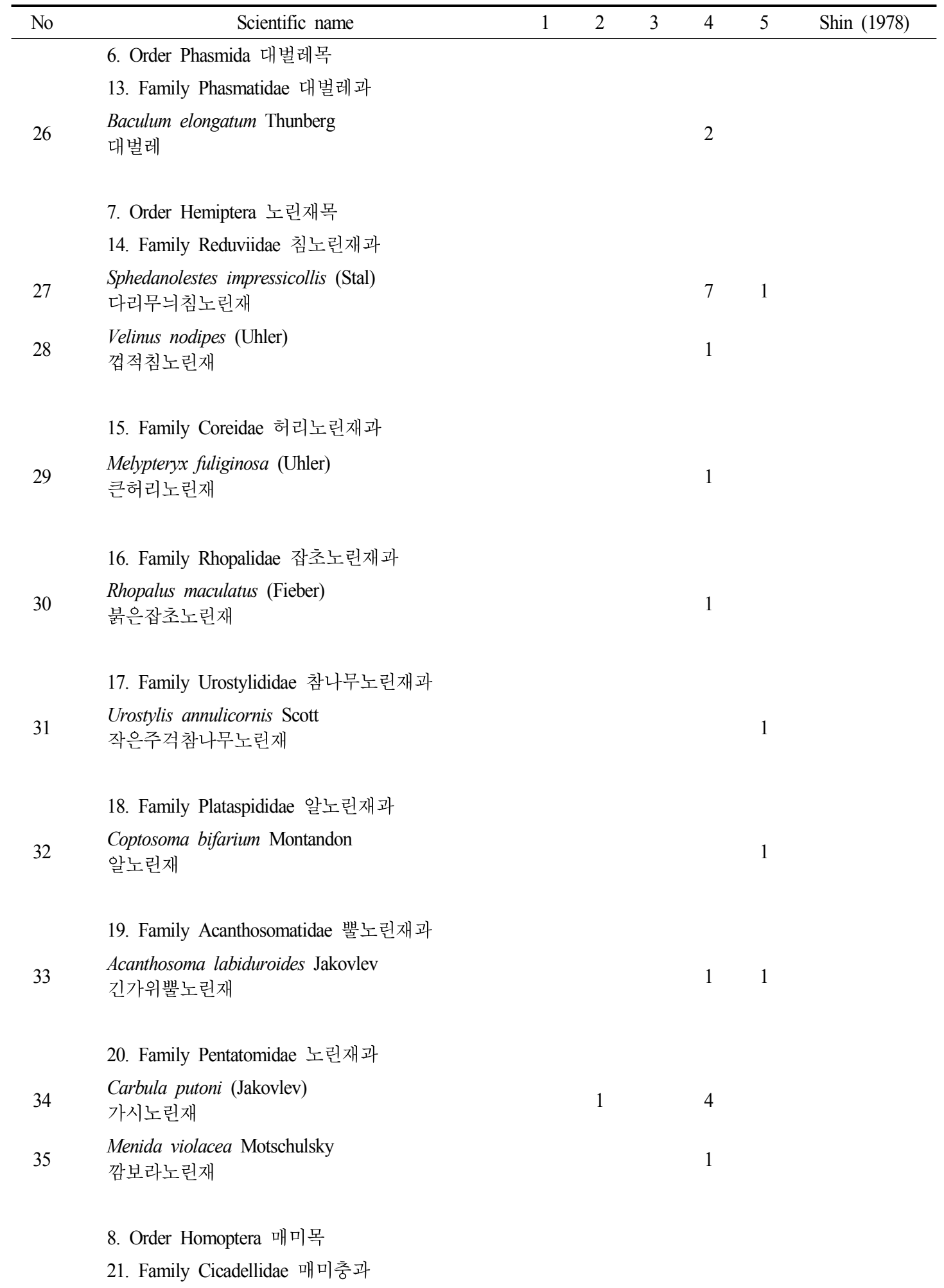




\begin{tabular}{|c|c|c|c|c|c|c|c|}
\hline No & Scientific name & 1 & 2 & 3 & 4 & 5 & Shin (1978) \\
\hline 36 & $\begin{array}{l}\text { Bothrogonia japonica Ishihara } \\
\text { 끝검은말매미충 }\end{array}$ & & 1 & 1 & 1 & 1 & \\
\hline & 22. Family Fulgoridae 꽃매미과 & & & & & & \\
\hline 37 & $\begin{array}{l}\text { Limois emelianovi Oshanin } \\
\text { 꽃매미 }\end{array}$ & & 1 & 1 & 2 & 1 & \\
\hline & 23. Family Cicadidae 매미과 & & & & & & \\
\hline 38 & $\begin{array}{l}\text { Cryptotympana dubia (Haupt) } \\
\text { 말매미 }\end{array}$ & 1 & & & & & \\
\hline 39 & $\begin{array}{l}\text { Graptopsaltria nigrofuscata (Motschulsky) } \\
\text { 유지매미 }\end{array}$ & 1 & & & & & \\
\hline 40 & $\begin{array}{l}\text { Oncotympana fuscata (Distant) } \\
\text { 참매미 }\end{array}$ & 1 & & & & & \\
\hline 41 & $\begin{array}{l}\text { Platypleura kaempferi (Fabricius) } \\
\text { 털매미 }\end{array}$ & 1 & & & & & \\
\hline 42 & $\begin{array}{l}\text { Suisha coreana (Matsumura) } \\
\text { 늦털매미 }\end{array}$ & & & 6 & & & \\
\hline
\end{tabular}

9. Order Coleoptera 딱정벌레목

24. Family Carabidae 딱정벌레과

$43 \quad$ Damaster jankowskii (Oberthür) 멋쟁이딱정벌레

25. Family Harpalidae 먼지벌레과

$44 \quad$ Dolichus halensis (Schaller) 등빨간먼지벌레

26. Family Brachinidae 폭탄먼지벌레과

45 Pheropsophus jessoensis Morawitz

폭탄먼지벌레

27. Family Silphidae 송장벌레과

$46 \quad$ Nicrophorus quadripunctatus Kraatz 넉점박이송장벌레

Thanatophilus sinutatus (Fabricius) 좀송장벌레

28. Family Lucanidae 사슴벌레과 


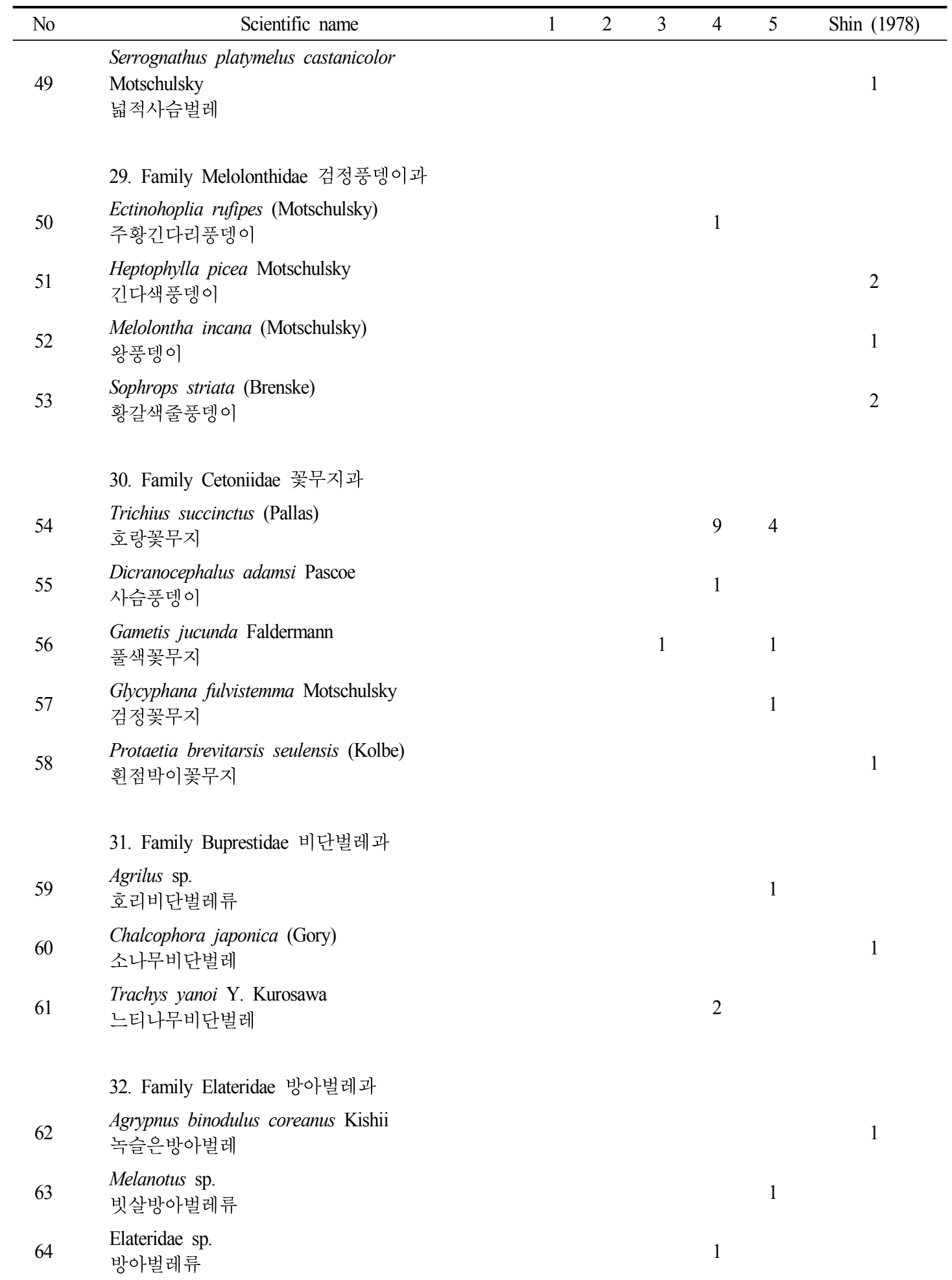




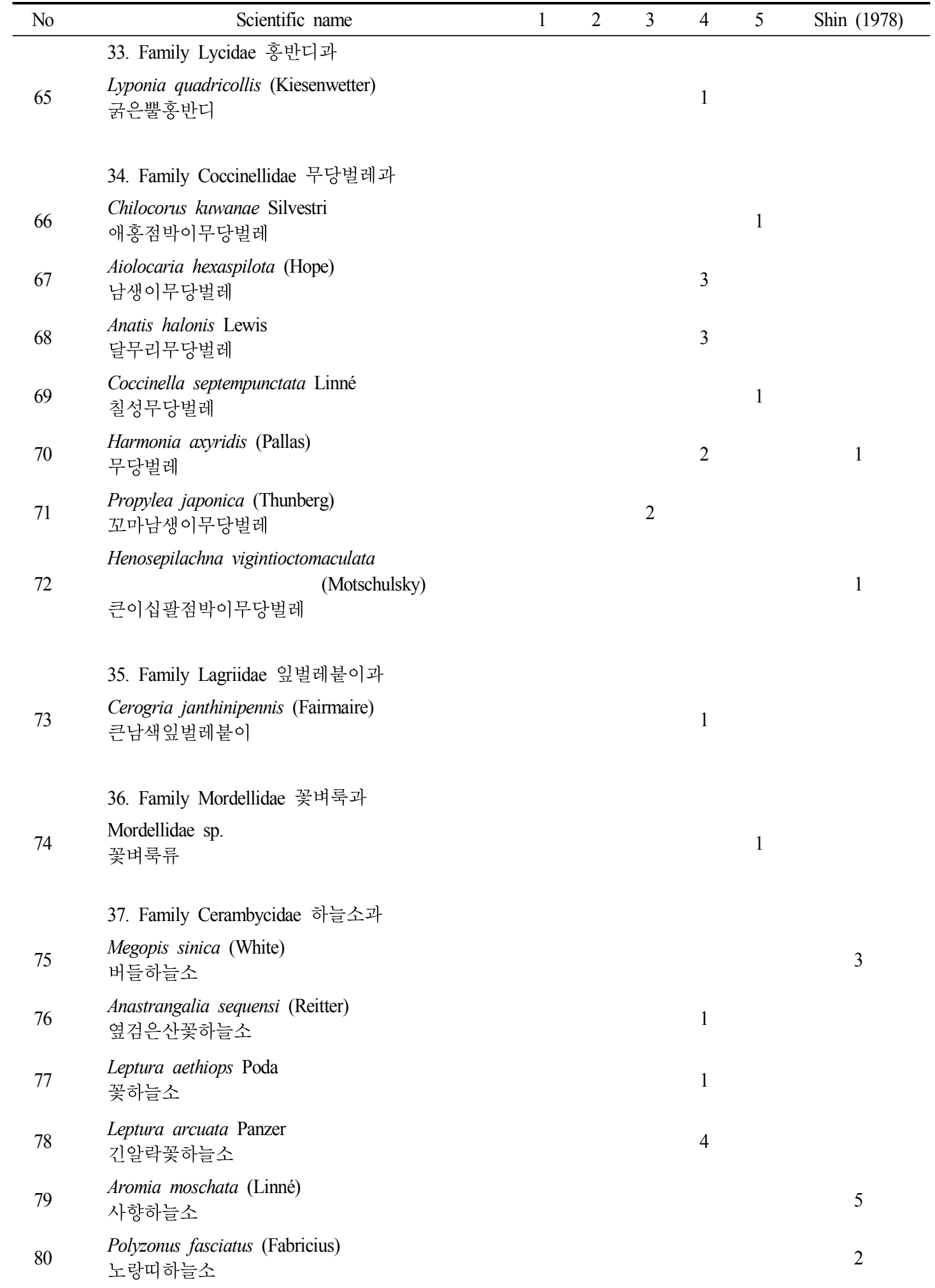




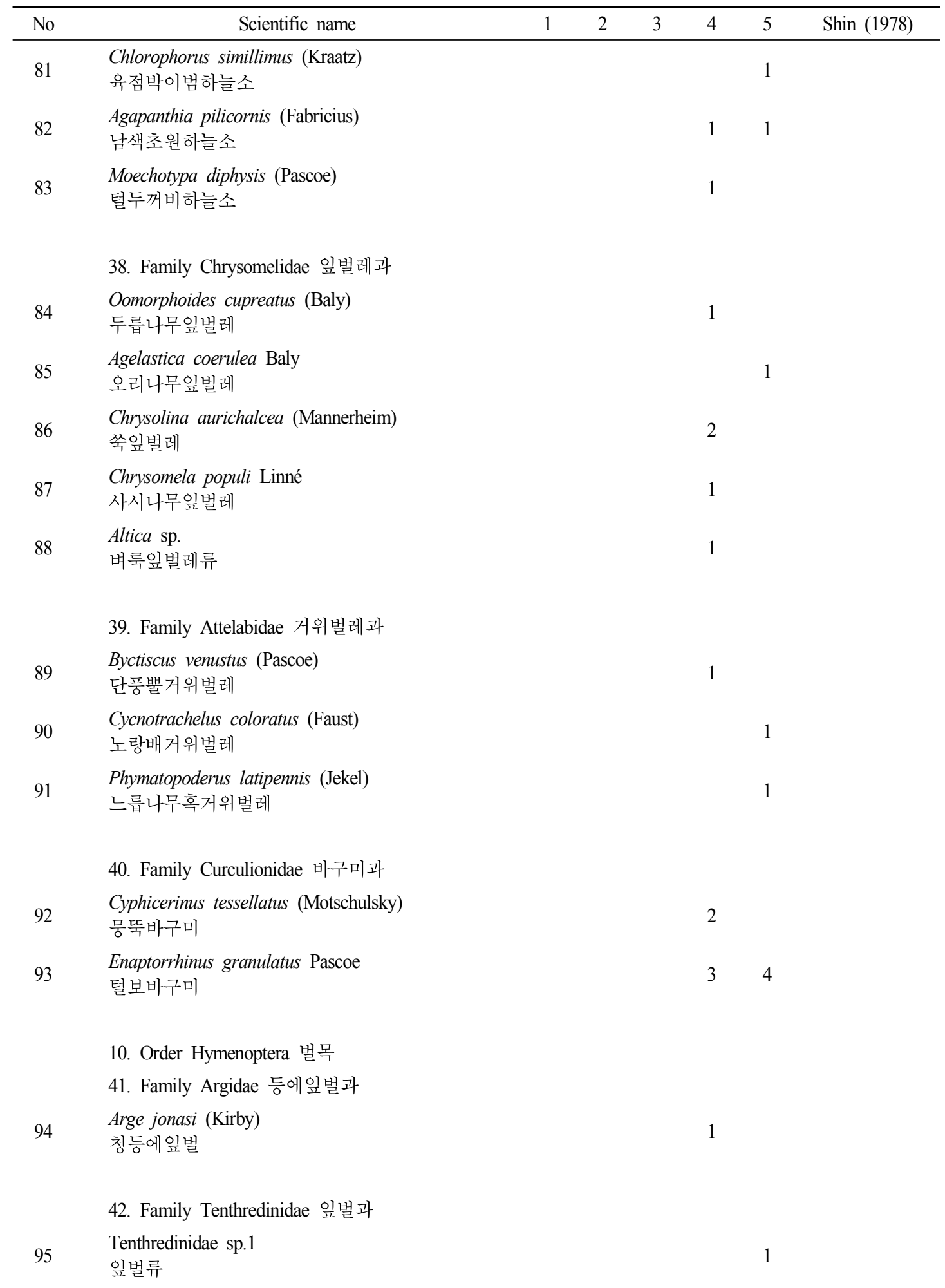




\begin{tabular}{|c|c|c|c|c|c|c|c|}
\hline No & Scientific name & 1 & 2 & 3 & 4 & 5 & Shin (1978) \\
\hline 96 & $\begin{array}{l}\text { Tenthredinidae sp. } 2 \\
\text { 잎벌류 }\end{array}$ & & & & & 3 & \\
\hline & 43. Family Scoliidae 배벌과 & & & & & & \\
\hline 97 & $\begin{array}{l}\text { Campsomeris schulthessi Betrem } \\
\text { 배벌 }\end{array}$ & 1 & & & & & \\
\hline & 44. Family Formicidae 개미과 & & & & & & \\
\hline 98 & $\begin{array}{l}\text { Camponotus japonicus Mayr } \\
\text { 일본왕개미 }\end{array}$ & & & & 1 & & \\
\hline 99 & $\begin{array}{l}\text { Formica japonica Motschulsky } \\
\text { 곰개미 }\end{array}$ & & & 2 & 1 & & \\
\hline & 45. Family Vespidae 말벌과 & & & & & & \\
\hline 100 & $\begin{array}{l}\text { Vespa crabro flavofasciata Cameron } \\
\text { 말벌 }\end{array}$ & & & & 1 & & \\
\hline 101 & $\begin{array}{l}\text { Vespula flaviceps lewisii (Cameron) } \\
\text { 땅벌 }\end{array}$ & & & 1 & 1 & & \\
\hline 102 & $\begin{array}{l}\text { Parapolybia varia (Fabricius) } \\
\text { 뱀허물쌍살벌 }\end{array}$ & & & & 1 & & \\
\hline 103 & $\begin{array}{l}\text { Polistes snelleni Saussure } \\
\text { 별쌍살벌 }\end{array}$ & & & & 1 & 2 & \\
\hline & 46. Family Apidae 꿀벌과 & & & & & & \\
\hline 104 & $\begin{array}{l}\text { Lasioglossum occidens Smith } \\
\text { 흰줄꼬마까꽃벌 }\end{array}$ & & & 1 & 1 & 3 & \\
\hline 105 & $\begin{array}{l}\text { Anthophora zonata Linné } \\
\text { 청줄벌 }\end{array}$ & 1 & & & & & \\
\hline 106 & $\begin{array}{l}\text { Xylocopa appendiculata circumvolans Smith } \\
\text { 어리호박벌 }\end{array}$ & & & & & 1 & \\
\hline 107 & $\begin{array}{l}\text { Apis mellifera Linné } \\
\text { 양봉꿀벌 }\end{array}$ & & & & & 51 & \\
\hline & $\begin{array}{l}\text { 11. Order Mecoptera 밑들이목 } \\
\text { 47. Family Panorpidae 밑들이과 }\end{array}$ & & & & & & \\
\hline 108 & $\begin{array}{l}\text { Panorpa coreana Okamoto } \\
\text { 참밑들이 }\end{array}$ & & 1 & & & 1 & \\
\hline 109 & $\begin{array}{l}\text { Panorpodes paradoxus MacLachlan } \\
\text { 모시밑들이 }\end{array}$ & & & & & 1 & \\
\hline
\end{tabular}




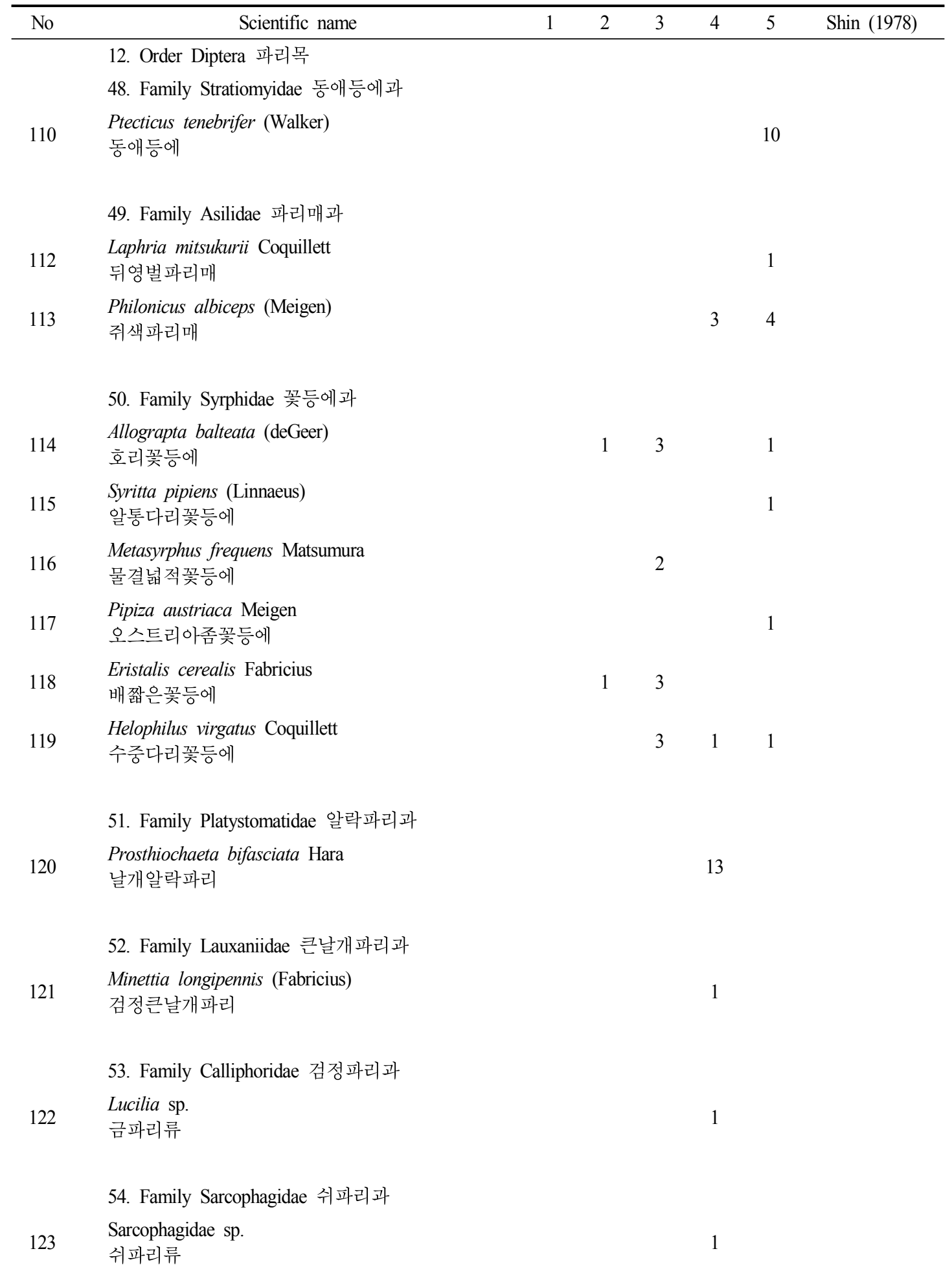




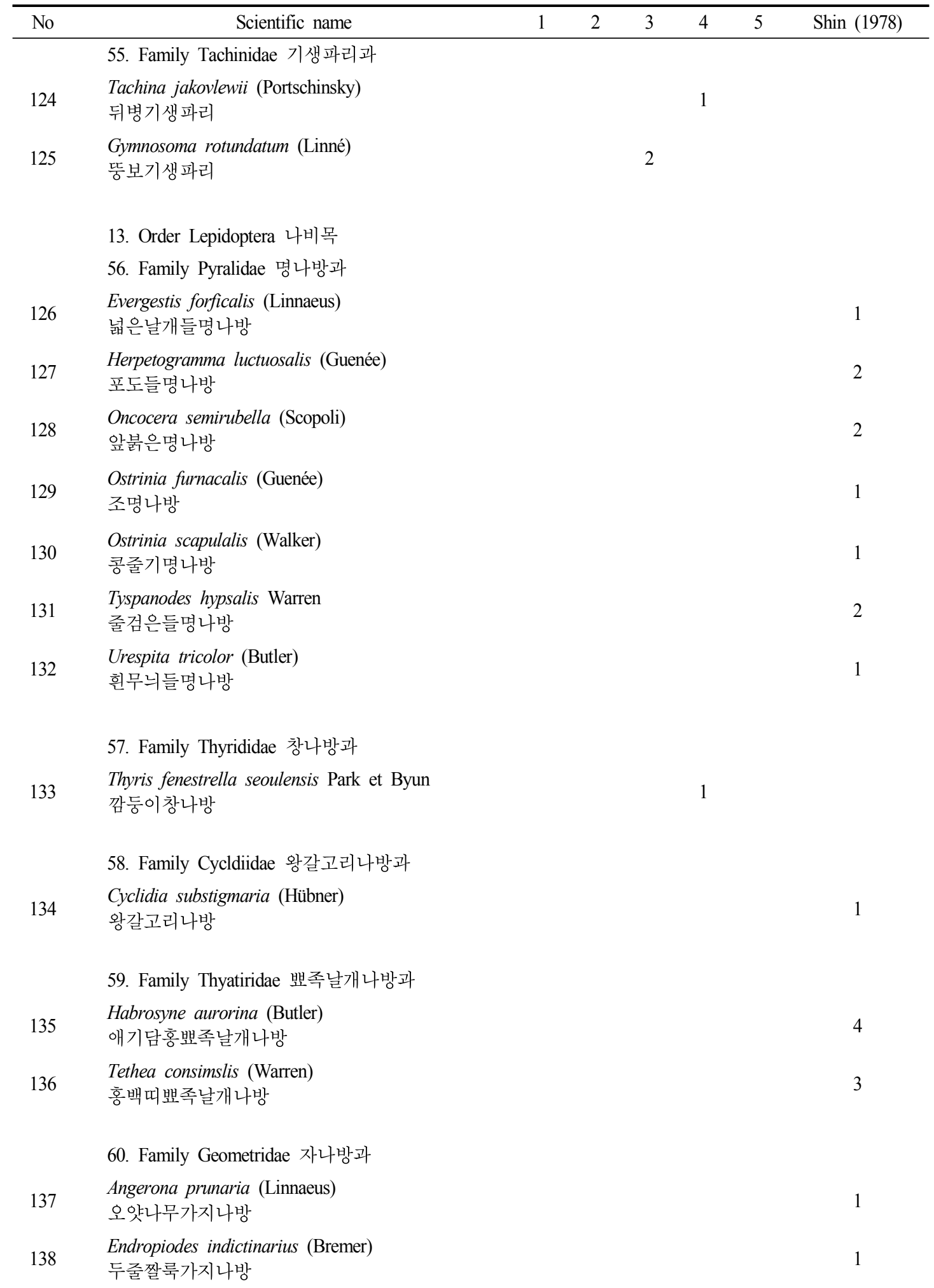




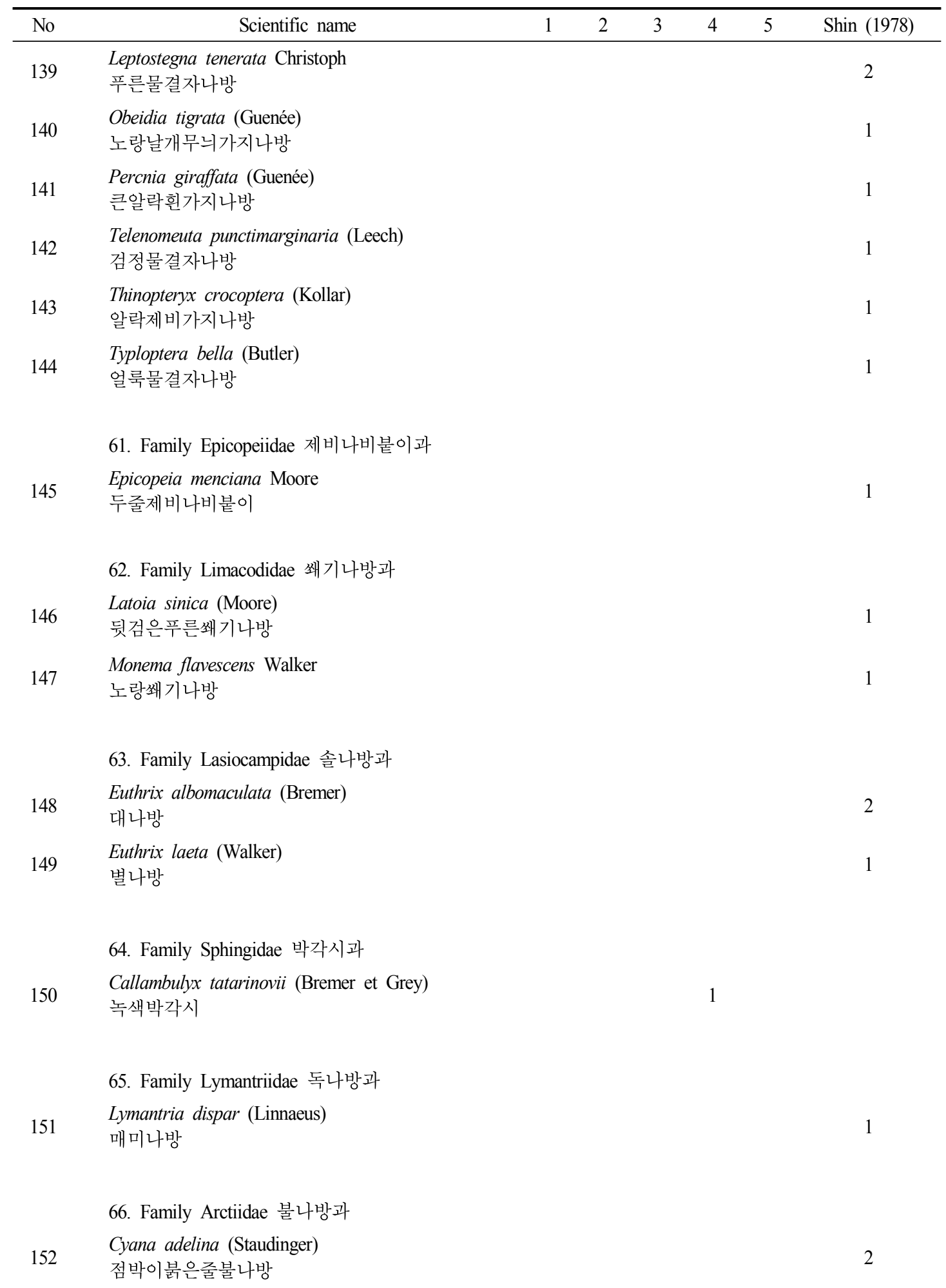




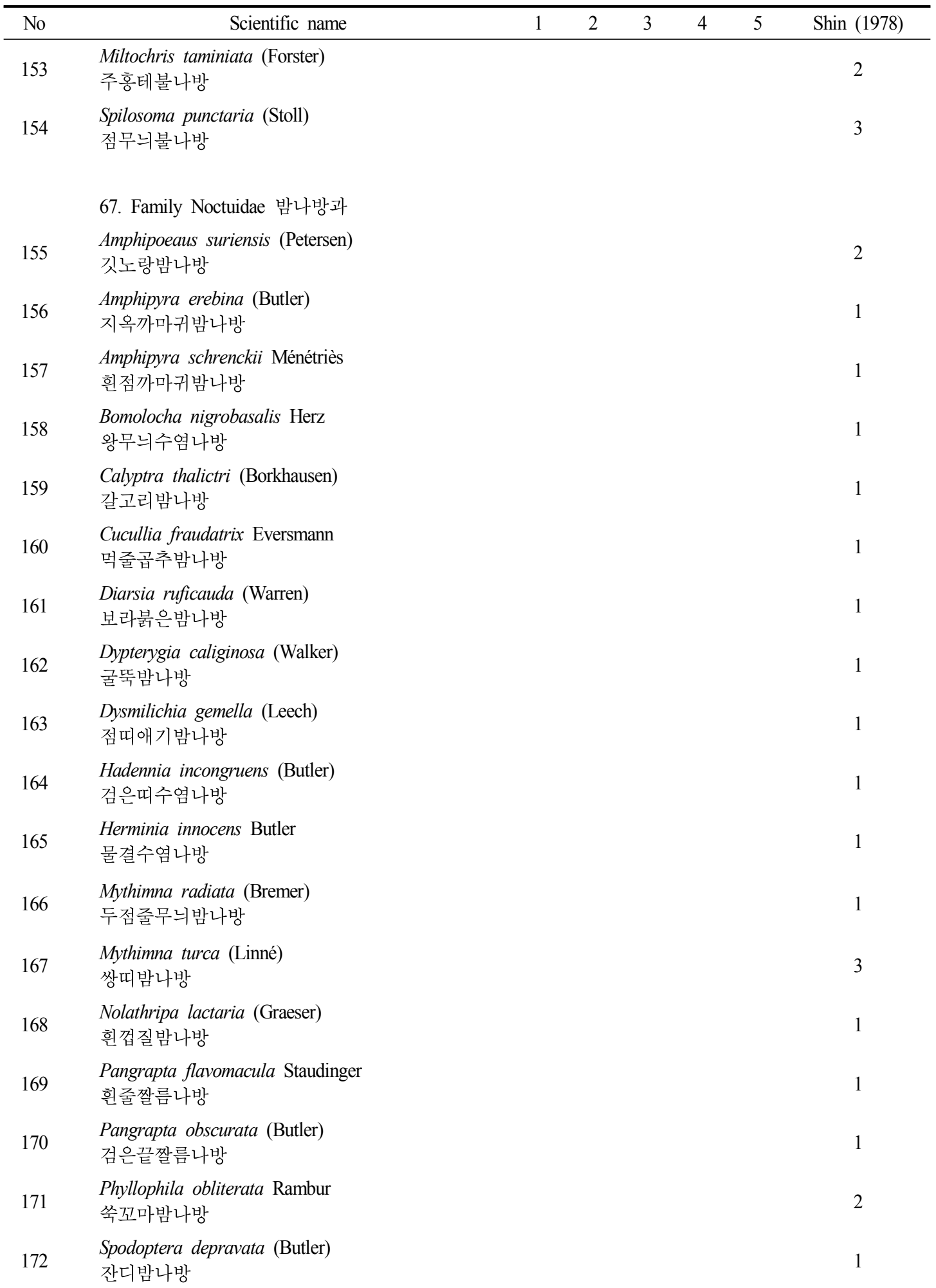




\begin{tabular}{lllllllc}
\hline No & \multicolumn{1}{c}{ Scientific name } & 1 & 2 & 3 & 4 & 5 & Shin (1978) \\
\hline 173 & $\begin{array}{l}\text { Sypnoides picta (Bremer) } \\
\text { 흰줄썩은잎밤나방 }\end{array}$ & & & & & & 1
\end{tabular}

68. Family Agaristidae 얼룩나방과

174 Sarbanis savenusta (Leech)

기생얼룩나방

69. Family Notodontidae 재주나방과

175 Peridea gigantea Butler

곧은줄재주나방

Spatalia dives Oberthür

176 세은무늬재주나방

70. Family Hesperiidae 팔랑나비과

177 Thymelicus sylvaticus (Bremer)

수풀꼬마팔랑나비

71. Family Papilionidae 호랑나비과

$178 \quad$ Atrophaneura alcinous (Klug)

사향제비나비

179 Papilio bianor Cramer

제비나비

180 Papilio maackii Ménétriès

산제비나비

181 Papilio xuthus Linnaeus 호랑나비

72. Family Pieridae 흰나비과

182

Artogeia canidia (Linnaeus)

대만흰나비

183 Artogeia melete (Ménétriès)

큰줄흰나비

184

185

Artogenia rapae (Linnaeus)

배추흰나비

Colias erate (Esper)

노랑나비

73. Family Lycaenidae 부전나비과

186 Japonica lutea $(\mathrm{H}$.

귤빛부전나비

Celastrina argiolus (Linnaeus)

푸른부전나비 


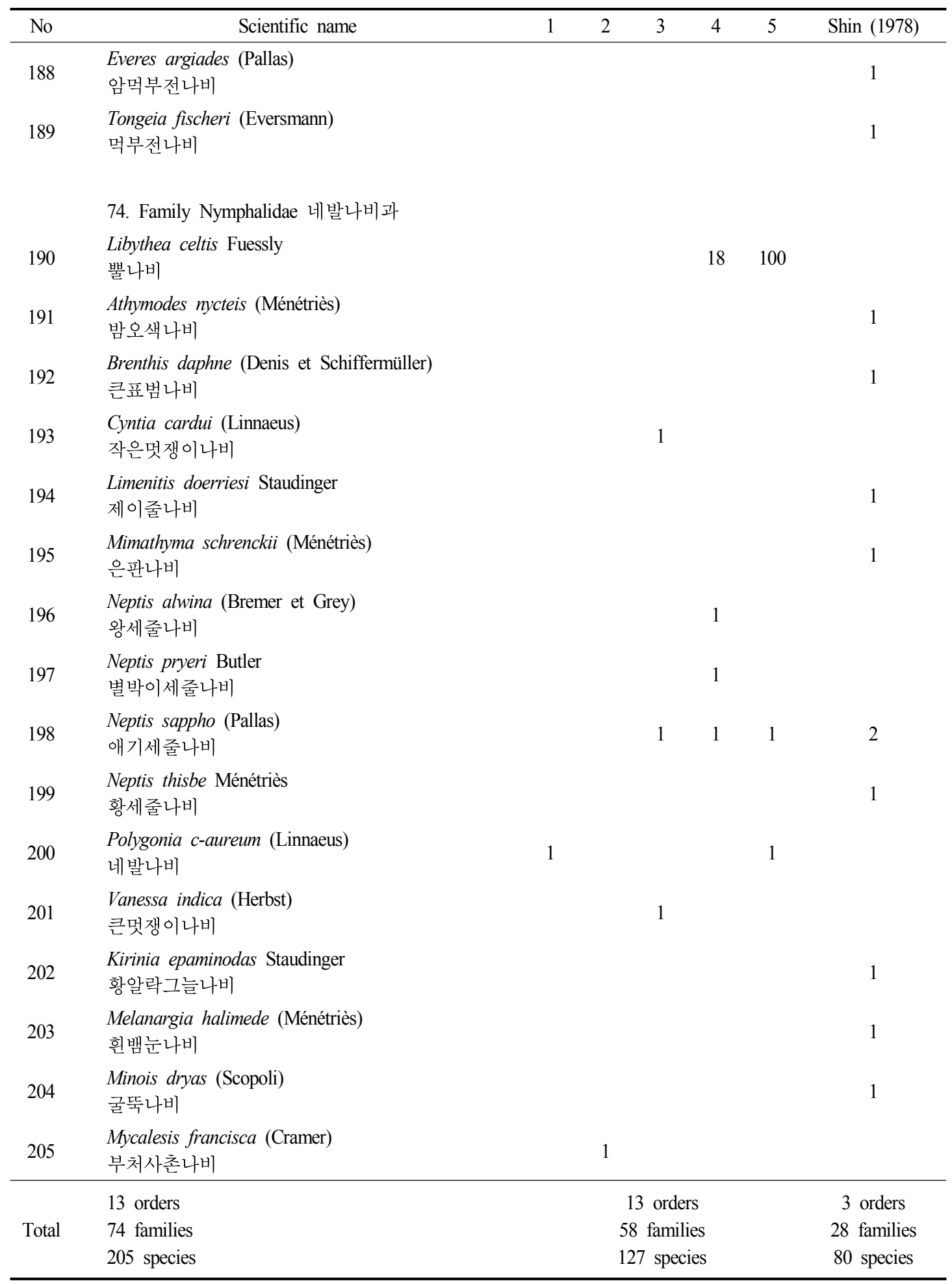




\section{인용문헌}

Asahina, S., T. Edashige, J. Hara, T. Hidaka, Y. Hirashima, S. Hisamatsu, T. Ishihara, R. Ishikawa, S. Ito, K. Kaneko, R. Kano, M. Kohno, M. Kurosawa, K. Kuwada, S. Miyamoto, M. Miyatake, Y. Miyatake, S. Momoi, T. Okada, M. Sasagawa, M. Sorin, T. Tachikawa, M. Takahawhi, I. Togashi, M. Tokunaga, C. Tsutsumi, H. Uchida, C. Watanabe, K. Yasumatsu, (2005) Iconographia Insectorum Japonicorum Colore naturali edita, Volumen III. Hokuryukan, Tokyo. 358 pp.

박해철, 김성수, 이영보, 이영준, 2006. Kyo-Hak Mini Guide 8. 딱정벌레. 교학사, 서울. 358 pp. 백문기, 황정미, 정광수, 김태우, 김명철, 이영준, 조영복, 박상욱, 이흥식, 구덕서, 정종철, 김기경, 최 득수, 신이현, 황정훈, 이준석, 김성수, 배양섭, 2010. 한국 곤충 총 목록. 자연과 생태, 서울. $598 \mathrm{pp.}$ 신유항, 1978. 월악산, 주흘산의 하계곤충상. 한국자연보존협회 조사보고서, 15: 135-146.

안수정, 김원근, 김상수, 2010. 한국의 자연생태1. 노린재 도감. 도서출판 필통, 서울. $294 \mathrm{pp}$. 이창언, 1979. 한국동식물도감. 제23권 동물편(곤충류VII). 문교부. $1,070 \mathrm{pp.}$

정광수, 2007. 한국의 잠자리 생태도감. 일공육사, 서울. $512 \mathrm{pp.}$

주흥재, 김성수, 손정달, 1997. 원색도감 한국의 나비. 교학사, 서울. $437 \mathrm{pp.}$

\section{요 약}

한국자연환경보존협회에서 주관한 주흘산종합학술조사를 통해 주흘산의 곤충상 조사가 이루어졌 다. 이번 조사는 크게 문헌 조사와 현지 조사로 수행되었다. 문헌 조사에서는 총 3 목 28 과 80 종이 주 흘산에 서식하는 것으로 보고된 바 있다. 이번 현지 조사를 통해서 13 목 58 과 125 종이 새롭게 확인되 었다. 따라서, 주흘산의 곤충상은 총 13 목 74 과 205 종으로 나타났다.

검색어 : 한국자연환경보존협회, 종합학술조사, 곤충상, 주흘산, 한국 